УДК 81-114.4

DOI: 10.12731/2077-1770-2017-4-248-255

\title{
КОНЦЕПТ «ХЛЕБ» \\ КАК ФРАГМЕНТ РУССКОГО \\ ЯЗЫКОВОГО СОЗНАНИЯ
}

\section{Макарова О.В.}

В статье представлен способ реконструкции концепта на материале ассоциативного эксперимента, который позволяет обнаруживать коллективные черты языковой общности. Цель исследования - выявить реальные смысль в сознании носителей языка, которые актуализируются в процессе вербальной реакции на слово-стимул «хлеб».

Наиболее характерные связи слов, отражающие особенности русской культуры, исследуются нами методом лингво-когнитивного анализа.

Концепт «Хлеб» в русской языковой картине мира включает представления, связанные не только с объектом вкуса, источником эмоций, но и своими признаками пересекается с различныли ментально-значимыли понятиями: «труд», «семья», «жизнь», «дом», «реньги» и др.

Набор когнитивных признаков при таком подходе к изучению структуры и содержания концепта значительно расширяется, $u$ язык предстает не как готовая абстракиия, максимально объективированная, а как система, свидетельствующая о ментально-эмоциональном состоянии его среднего носителя в определенный исторический период.

Результаты исследования могут быть применены для разработки курсов, посвящённых когнитивной лингвистике, психолингвистике, семантике.

Ключевые слова: концепт; языковое сознание; ассоциативный тезаурус; поле, когнитивные признаки. 


\section{CONCEPT «BREAD» AS A FRAGMENT OF THE RUSSIAN LANGUAGE CONSCIOUSNESS}

\section{Makarova O.V.}

This paper researches the way of concept building based on the collective features of local lingual community, which were obtained during the associative experiment. The point of research is to find out the meaning being actualized by the "Bread" concept, using lingual-cognitive analysis.

The "Bread" concept includes the ideas, which are connected not only by the taste object as an emotional source, but also by different cultural concepts, such as "Labour", "Family", "Life”, "Home”, "Money”. In this way of concept researching, its content is widened to the mental system of its medium in a certain historical period.

The results of the research can be applied to develop courses on cognitive linguistics, psycholinguistics, and semantics.

Keywords: concept; linguistic consciousness; associative thesaurus; field, cognitive features.

Одним из способов реконструкции концептов и других ментальных репрезентаций как фрагментов «коллективного сознания» является ассоциативный эксперимент. Это дает основания рассматривать «Русский ассоциативный словарь» в качестве своеобразной модели сознания человека $[1$, с. 5], включающей, по утверждению Ю.Н. Караулова, «весь или почти весь языковой опыт наивно говорящего индивида» [3, с. 8$]$.

Специфика массового ассоциативного эксперимента заключается в том, что в процессе его проведения индивидуальные черты языковой личности стираются, что заставляет говорить о «нормах», свойственных той языковой общности, к которой принадлежит эта личность» [3, с. 120]. Принадлежность к одной культуре делает центр ассоциативного поля стабильным, а связи - регулярно воспроизводимыми. В связи с этим ассоциа- 
тивное поле слова может рассматриваться как фрагмент образов сознания русских.

Объектом нашего исследования является лексическое наполнение ассоциативного поля «хлеб», представленное 625 реакциями на заданное слово-стимул. Материал словаря не организован логически и иерархически, он представляет собой «мозаический набор скрытых в языковых структурах умозаключений об устройстве мира, мотивировки которых опираются на традицию, общепринятость, устойчивость, воспроизводимость и повторяемость» [3, с. 89].

Задача заключается выявлении способов репрезентации концепта «Хлеб» в языковом сознании индивида на основе анализа данных ассоциативного эксперимента.

Решение задачи обусловило использование лингво-когнитивного метода, интегрирующего приемы компонентного и логико-семантического анализа.

Научная новизна исследования заключается в том, что подход к анализу понятия с позиций языкового сознания индивида позволяет расширить границы теоретических описаний структуры сознания. Изучение только словарных компонентов смысла, а также функционального потенциала слова недостаточно для целостной характеристики концепта.

Развиваемые в работе идеи могут использоваться для разработки вузовских курсов, посвящённых когнитивной лингвистике, психолингвистике, семантике.

Концепт «Хлеб» занимает особое место в русской языковой картине мира. Важность данного понятия подчеркивается не только в большом количестве фразеологизмов, паремий, в календарной поэзии и других жанрах русской литературы, но и тем, что хлеб в России - больше, чем пропитание, «он - символ пропитания». Так, если во Франции, Испании нищий просит «на чашечку кофе», в России - «на кусок хлеба» [4, с. 284]. Понятие хлеба как главного продукта в индоевропейской культуре связано и с более общими представлениями «распределителя благ» - «хозяина» и даже «Бога» [4, с. 208]. 
Изучив данные ассоциативного эксперимента в виде реакций на слово-стимул «хлеб», мы выявили следующие признаки исследуемого концепта:

1. Парадигматические реакции указывают на цель восприятия хлеба (сытость), следствие (яд), условие существования субъекта восприятия (пропитание), средство к существованию человека (заработок), способ восприятия хлеба (на ужин, стол),

Среди представленных реакций можно выделить те, которые находятся с именем поля в гиперо-гипонимических или синонимических отношениях: пища (6), еда (4); булка (14), каравай (5), батон, буханка (4), лаваш, сухарь, соломка, бутерброд (1).

Много реакций выражают отношение к данной реалии (святыня, золото, драгоценность и др.) и содержат эмоциональный компонент. Причем значение таких номинаций осложнено коннотативными смыслами: культурологическими, религиозными и этическими. Так, реакция «Христос» связана с религиозными представлениями данного социума, в соответствии с которыми хлеб - это тело Христово, а значит - святыня.

Связь хлеба и народных традиций, обычаев подчеркивается следующими ассоциациями: балалайка, каравай, на ужин, стол. Русский народный инструмент «балалайка» в этом ряду, по-видимому, упоминается в связи с обычаем застолья, обязательным атрибутом которого всегда был каравай.

Хлеб является символом благополучия, материального достатка: богатство (6 реакций), наше богатство (2), золото (2), драгоценность, дорогой, беречь.

Метафорический способ репрезентации концепта «хлеб» представлен особенно широко. Семантическая деривация компонентов пропозиции вкусового восприятия свидетельствует о значимости исследуемого понятия для человека. Хлеб уподобляется следующим явлениям и предметам действительности: науки, промышленности; камень, всему голова!, голова, жизнь, свет, величина, вещь уникальная. В основе данный реакций содержится как эмпирический (тактильный) аспект оценки (камень), так и эмоциональный 
и интеллектуальный виды оценки этого атрибута жизни человека (хлеб науки, промышленности; свет).

В исследуемом тезаурусе встречается и прецедентное высказывание (хлеба и зрелищ), знание которого свидетельствует о принадлежности говорящих к русской лингвокультурной общности.

Хлеб рассматривается как источник эмоций: радость, горький. Значение атрибута «горький» осложняется эмоциональной оценкой: горький хлеб - значит добываемый тяжелым трудом.

2. Синтагматические реакции характеризуют хлеб как объект восприятия (вкусный (21), вкус, вкусное), причем характеристика хлеба является полимодальной: он оценивается с позиции разных подсистем восприятия. Обонятельные ассоциации хлеба: запах, запах хлеба, душистый, ароматный; осязательные реакции: сухой, мягкий, свежий, черствый, жесткий, теплый, горячий; слуховые: с хрустящей корочкой; зрительные: черный (30), бельй (23), кругльій, круг, пышиный. Значимость данного понятия подчеркивается тем, что ряд ассоциаций связан с размером хлеба: кусок (3), корка, корочка, крошки.

Хлеб связан с такими объектами восприятия, как: соль (14), $u$ соль (3), да соль (2), масло (7), молоко (5), и вода (2), сок (1), чай (1).

Исследуемое поле «хлеб» отражает также синтагматические отношения, указывающие на способ приготовления (испечь); инструмент/средство действия (резать, нож); процесс восприятия и его оценку (есть, кушать, жрать, жевать); место нахождения данного объекта вкуса (на столе, в ведре, в тарелке); временной план процесса восприятия (всегда); адресата, того, кому предназначается этот объект восприятия (народу, народам).

Респонденты в своих ответах указывают и на релевантность способа получения хлеба: купить, магазин - и сорт данного продукта: ржаной (22), пшеничный (4), орловский (1), подовый (1), ситныцй (1).

В составе совокупного ассоциативного поля «хлеб» может быть выделено ядро - группа словоформ, в значении которых имеется указание на то, что хлеб - это объект восприятия вкуса и, прежде 
всего, необходимый, насущцный (58 реакций) источник жизни (6 реакций).

Хлеб выступает также в роли объекта оценки: настоящиий, хороший, общий, единый, дорог нам. Ряд реакций свидетельствует об отрицательном отношении к данному объекту восприятия: равнодушно, плохой.

3. Когнитивный уровень репрезентации концепта «Хлеб» представлен такими реакциями, которые позволяют обнаружить пересечение с другими ментальными репрезентациями, например, фреймом «кухня» (на ужин, стол, нож, резать и др.), фреймом «ситуация вкусового восприятия» (ecmb, вкус, душистый, соль). Кроме этого, достаточно последовательно проявляется в ассоциативном тезаурусе связь концептов «Хлеб» и «Семья, Дом»: мама, жена, кухня, печь. Отражено в ассоциативном тезаурусе и взаимное пересечение концептов «Хлеб» и «Борьба»: война, мир, наган, свободный.

Связь концептов «Хлеб» и «Пространство» опирается большей частью на активизацию в сознании испытуемых представлений о месте его нахождения: в магазине, на столе, в ведре, в тарелке, на поле.

Представление о хлебе как о недорогом, но необходимом атрибуте жизни человека, особенно для сирот (1) эксплицирует связь с концептом «Деньги»: дорогой, бельй за 25 копеек, экономить. Данный ряд реакций позволяет выделить в сознании русских оппозицию «богатый - бедный». Кроме этой оппозиции реакции респондентов позволяют вычленить и оппозицию «свое - чужое»: наш, наше богатство, дорог нам, русский.

4. Прагматические реакции, представленные в форме диалога, как реплика партнера: не хочу, береги, берегите.

Таким образом, представление о хлебе в основном вербализуется ассоциациями, характеризующими его как источник вкуса, без которого не может жить человек. Этот факт подтверждает и словари, так, в словарной статье лексемы «хлеб» содержится указание на то, что это основной пищевой продукт какой-либо страны, местности [2, c. 936]. 
Способы репрезентация концепта «Хлеб», представленные словарными значениями исследуемого понятия, включают такие признаки, как: объект вкусового восприятия (продукт), способ изготовления (из муки), форму (буханка, батон, каравай) - прямые номинации; условие существования субъекта восприятия (пропитание, пища), средство к существованию человека (заработок) - переносные номинации. Как видим, в лексическом значении слова отображается не вся совокупность признаков понятия, а только существенные, социально закрепленные (5 когнитивных признаков концепта «Хлеб»). В ассоциативном тезаурусе мы обнаруживаем актуальные вербальные связи слова-стимула с другими словами, репрезентируемые в сознании носителей языка (зафиксировано 39 когнитивных признаков концепта «Хлеб»).

Хлеб в ассоциативном тезаурусе, отражающем наивное представление «коллективного субъекта» о мире, предстает как явление одновременно «духовное» и «материальное», сквозь призму которого можно реконструировать модель русского человека, оценить его качества и предпочтения.

\section{Список литературы}

1. Ассоциативный тезаурус современного русского языка. М.: «Помовский и партнеры», 2004. 198 с.

2. Ефремова Т.Ф. Новый словарь русского языка. Толково-словообразовательный: В 2 т. М.: Русский язык, 2000. Т. 2. 1084 с.

3. Караулов Ю.Н. Ассоциативная грамматика русского языка. М.: Русский язык, 1993. 143 с.

4. Степанов Ю.С. Константы. Словарь русской культуры. М.: Академический проект, 2001. 990 с.

\section{References}

1. Assotsiativnyy tezaurus sovremennogo russkogo yazyka [The associative thesaurus of the contemporary Russian language]. M.: «Pomovskiy i partnery», 2004. $198 \mathrm{p}$. 
2. Efremova T.F. Novyy slovar' russkogo yazyka. Tolkovo-slovoobrazovatel'nyy [The new dictionary of the Russian language. Interpretative and word-building]: V 2 t. M.: Russkiy yazyk, 2000. T. 2. 1084 p.

3. Karaulov Yu.N. Assotsiativnaya grammatika russkogo yazyka [The associative grammar of the Russian language]. M.: Russkiy yazyk, 1993. $143 \mathrm{p}$.

4. Stepanov Yu.S. Konstanty. Slovar' russkoy kul'tury [Constants. The dictionary of the Russian culture]. M.: Akademicheskiy proekt, 2001. 990 p.

\section{ДАННЫЕ ОБ АВТОРЕ}

Макарова Ольга Владимировна, доцент кафедры филологических дисциплин, кандидат филологических наук

Тюменский государственный медицинский университет

ул. Одесская, 54, г. Тюмень, 625023, Российская Федерация omakarova1980@mail.ru

\section{DATA ABOUT THE AUTHOR}

Makarova Olga Vladimirovna, Associate Professor, Department of philological disciplines, Ph. D. in Philology

Tyumen State Medical Academy

54, Odesskaya Str., Tyumen, 625023, Russian Federation

omakarova1980@mail.ru

SPIN-code: 5658-9943

ORCID: 0000-0002-3356-6794 